\title{
Effect of antigen load on development of milk antibodies in infants allergic to milk
}

\author{
M A FIRER, C S HOSKING, D J HILL
}

\begin{abstract}
The phenomenon that large amounts of antigen, such as are absorbed during the neonatal period, suppress the IgE response while low-dose exposure enhances it was investigated by analysing the antibody responses of infants allergic to milk according to their degree of exposure to cows'-milk protein. IgG, IgA, and IgM milkspecific antibodies in these infants and in age-matched controls were measured by enzyme-linked immunosorbent assay. Milk-specific IgE and total IgE were also measured. Children allergic to milk who were breast fed and had had minimal exposure to cows' milk had decreased titres of $\operatorname{IgG}, \operatorname{IgA}$, and $\operatorname{IgM}$ milk antibodies compared with infants allergic to milk who, before diagnosis, had been fed substantial volumes of cows' milk. Conversely, the infants with minimal exposure to cows' milk showed vastly increased total and milkspecific IgE antibodies compared with the milk-fed infants.

These results support recent experimental evidence that appreciable amounts of allergen suppress rather than stimulate IgE production. These data may have important implications for dietary regimens in at-risk infants. The results also lend support for the role of $\mathrm{IgE}$ in immediate-type allergic reactions and suggest that various non-IgE immune mechanisms play a part in the aetiology of intolerance to cows'-milk protein in some children.
\end{abstract}

\section{Introduction}

The observed relation between the diminished incidence of allergic symptoms in children exclusively breast fed or fed lowantigen diets : has stimulated two hypotheses regarding the allergic sensitisation of atopic children by dietary antigens.

Royal Children's Hospital, Parkville, Victoria, Australia 3052 M A FIRER, BSC, research student, department of immunology C S HOSKING, MD, FRACP, director, department of immunology D J HILL, MB, FRACP, consultant allergist
The first suggestion is that allergic illness may be due to overstimulation of an otherwise normal immune mechanism by excess contact with antigen. This may be caused by a defect in mucosal handling of the antigen or in the control of the response to it. ${ }^{3-5}$ Such a defect would allow excessive absorption of an antigen directly stimulating IgE-secreting plasma cells at the mucosal surface leading to sensitisation. ${ }^{6}$ The association of transient IgA deficiency with subsequent development of atopy supports these concepts. ${ }^{3:}$

The other possibility is that normal subjects absorb enough antigen across the mucosal barrier to activate IgE-suppressor $\mathrm{T}$ cells, causing inhibition, not stimulation, of the IgE responses.? This hypothesis is supported by experimental and clinical studies, which have shown that the normal intestinal and respiratory mucosa permit the absorption of food and inhaled antigens in amounts that are unimportant nutritionally but important immunologically. ${ }^{4} 89$ Whereas these small antigen doses stimulated the antigen-specific IgE response in rats, ${ }^{10}$ Jarrett et al found that the response was suppressed when the animals were fed excess amounts of antigen." Experimental evidence suggests that secretory IgA limits mucosal absorption of antigen. ${ }^{6} 12$ Thus a transient mucosal IgA deficiency should enhance absorption of antigen and lead to suppression rather than stimulation of the IgE response. This suggests that the association between IgA deficiency and allergy may not be cause and effect. ${ }^{3}$

We do not know of any studies that have shown an effect of high-dose antigen exposure operating in suppression of the IgE response in the newborn and infant period as suggested by the observations of Jarrett $e t$ al on rats. The possibility that some of the different immunological responses seen in children allergic to milk may be related to their degree of exposure to cows'-milk proteins was examined by analysing the antibody responses to food of a group of children with confirmed allergy to cows' milk according to their degree of exposure to cows'milk protein.

\section{Patients}

From a group of 54 children allergic to cows' milk, 24 for whom an adequate feeding history was available were included in this study.

The diagnosis of allergy to cows' milk was based on the protocol previously described. ${ }^{13}$ Each child was stabilised on a diet free from 
cows'-milk proteins for at least four weeks before admission to hospital for formal milk challenge. Commercially pasteurised cows' milk was used in an initial dose of $0 \cdot 5-5.0 \mathrm{ml}$. If no response occurred within 30 minutes the volume was doubled at hourly intervals until a positive response was elicited.

The symptomatic response to milk provocation was defined as (1) acute: gastrointestinal reactions or skin eruptions occurring within one hour of challenge; (2) intermediate: gastrointestinal reactions or skin eruptions occurring between one and 24 hours; and (3) late: reactions occurring more than 24 hours after the start of milk challenge. Patients with late reactions were ingesting normal volumes of cows' milk for their age when symptoms developed.

From information obtained from the clinical history the infants were divided into two groups according to their degree of exposure to cows' milk.

Group $A$ consisted of 10 breast-fed infants who had developed acute symptoms immediately on beginning weaning to cows' milk. The volume of cows' milk that precipitated symptoms was small $(<60 \mathrm{ml})$, and before blood was taken they had had no more than two such feeds. On each occasion the milk given precipitated a reaction. No detailed history of feeding in the neonatal nursery was available. All had acute vomiting or diarrhoea, or both; five also experienced acute angio-oedema or urticaria after ingesting milk.

Group $B$ consisted of 13 children who had received either substantial volumes of milk $(60 \mathrm{ml})$ on more than two occasions or small volumes $(30-60 \mathrm{ml})$ at frequent intervals over a period of months. Nine had been breast fed but four had been fed cows' milk from birth. Exposure to cows' milk produced a similar range of symptoms to those in group A. Two infants had acute skin eruptions with vomiting or diarrhoea, or both, while eight had episodes of only acute vomiting or diarrhoea. The remaining three developed vomiting and diarrhoea between six and 24 hours after ingesting milk.

The infants in groups A and B were of similar age and were breast fed for comparable lengths of time (see table). Nineteen infants matched for age with groups A and B made up the control population (group $\mathrm{C}$; see table). These patients had been admitted to hospital for various medical and surgical conditions unrelated to allergy to cows' milk. No adequate feeding information, however, was available for these infants.

Age distribution and breast feeding data for patients at time of sampling for groups $A, B$, and $C$. Ranges given in parentheses

\begin{tabular}{ccccc}
\hline Group & $\begin{array}{c}\text { No of } \\
\text { infants }\end{array}$ & $\begin{array}{c}\text { Median age } \\
\text { (months) }\end{array}$ & $\begin{array}{c}\text { No } \\
\text { breast } \\
\text { feeding }\end{array}$ & $\begin{array}{c}\text { Duration of } \\
\text { breast feeding } \\
\text { (months) }\end{array}$ \\
\hline A & 10 & $7(5-9)$ & 10 & $6(3-12)$ \\
B & 13 & $9(3-24)$ & 9 & $4(0-20)$ \\
\hline
\end{tabular}

The children allergic to milk were allocated to group A or group $B$ by each of us independently, without knowledge of the antibody values. Agreement was reached on all but two cases, in which the patient could have fitted into either group. Subsequent analysis of the results with these patients in each of the nominated groups did not alter the significance of the results.

\section{Materials and methods}

Serum immunoglobulin estimation-Total IgG, IgA, and IgM values were measured with an autoanalyser fluoronephelometer (Technicon) and expressed as percentile values according to the age of the patient. ${ }^{14}$ Total IgE was measured in IU/ml using the Phadebas IgE PRIST kit (Pharmacia Diagnostics, Uppsala, Sweden).

Food-specific antibodies-Milk-specific IgG, IgA, and IgM antibodies were measured using an enzyme-linked immunosorbent assay developed in our laboratory. ${ }^{15}$ Fresh, pasteurised, fat-free cows' milk was allowed to bind to microtitre plates (Disposable Products Pty Ltd, South Australia). After incubation and washing, serum was added, allowing milk-specific antibody to attach to the adhered milk proteins. After the incubation period unabsorbed serum was washed off. The absorbed milk-specific antibodies were identified by adding the appropriate rabbit antihuman serum (DAKO) coupled to alkaline phosphatase (SIGMA Chemicals, St Louis, USA). After incubation and washing, the optical density of the colour reaction produced by adding substrate ( $p$-nitrophenyl phosphate) was read at $410 \mathrm{~nm}$ on an enzyme-linked immunosorbent assay colorimeter. This was used as a direct measure of the amount of milk-specific antibodies present. These measurements of optical density were converted to $\mathrm{IgG}, \mathrm{IgA}$, or IgM milk antibody units by comparison with a high-titred laboratory standard.

IgE antibodies to milk were measured with a radioallergosorbent test kit (Phadebas) and the absolute counts per minute of isotope bound to allergen-specific IgE measured to permit direct comparison of specific IgE in controls and patients. All the tests were performed with the same batch of reagents. The radioallergosorbent test scoring scale was not used.

Statistical analysis-The Mann-Whitney U test was used throughout to assess differences in antibody values between the groups. The null hypothesis was rejected when $\mathrm{p}<0.05$.

\section{Results}

Serum immunoglobulin estimation-No significant differences were seen between the groups in total IgG or IgA. The patients allergic to milk (groups $A$ and $B$ ) had significantly lower percentile values of IgM than age-matched controls (group C). Several minor abnormalities in immunoglobulin concentrations were noted in all groups, but no consistent trends were observed. The total serum IgE values in group A were significantly higher than those in groups $B$ and $C$. No differences were observed between groups B and C (fig 1).

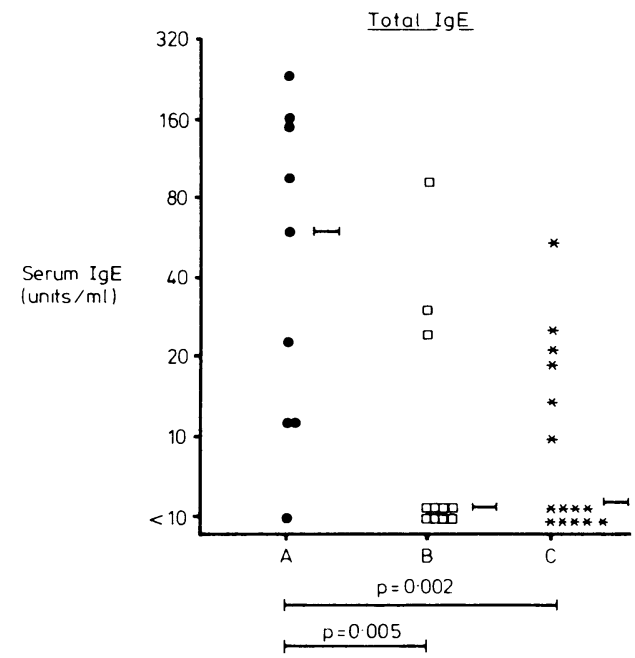

FIG 1-Total serum IgE concentrations in the two patient groups and controls measured by PRIST. A - Milk-restricted patients with allergy to cows' milk. B Non-milk-restricted patients with allergy to cows' milk. C $=$ Age-matched controls.

Food-specific antibodies-The median IgG, IgA, and IgM milk antibody values were lower in group A than in group B (fig 2). These differences were significant only for $\operatorname{IgA}$ and $\operatorname{IgM}$. In both groups IgG milk antibodies were significantly lower than in age-matched controls. Milk-specific IgE antibody values in group A were significantly higher than those in groups $\mathrm{B}$ and $\mathrm{C}$ (fig 3). No differences in specific IgE antibody values were seen between groups $B$ and C.

\section{Discussion}

Our results suggest that in infants allergic to cows' milk lowdose antigen stimulation is associated with the development of an IgE hypersensitivity disorder, whereas ingestion of large amounts of cows'-milk protein favours the development of IgA, IgM, and possibly IgG, but not IgE, antibodies. A similar relation between allergen exposure and serum $\mathrm{IgE}$ response was recently observed in infants with a family history of allergy. ${ }^{10}$ 


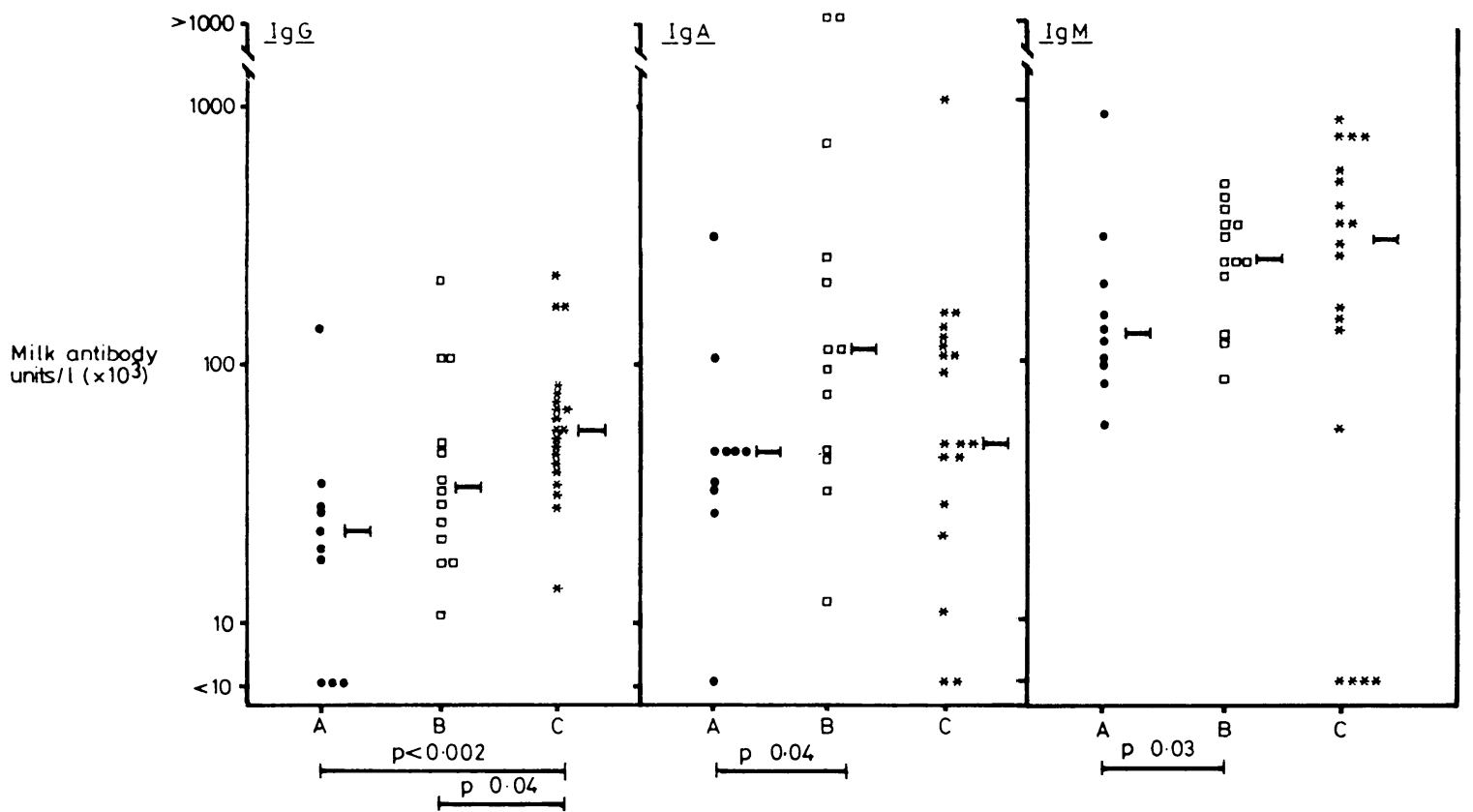

FIG 2-Milk-specific IgG, IgA, and $\operatorname{IgM}$ antibodies in the two patient groups and controls measured by enzyme-linked immunosorbent assay.

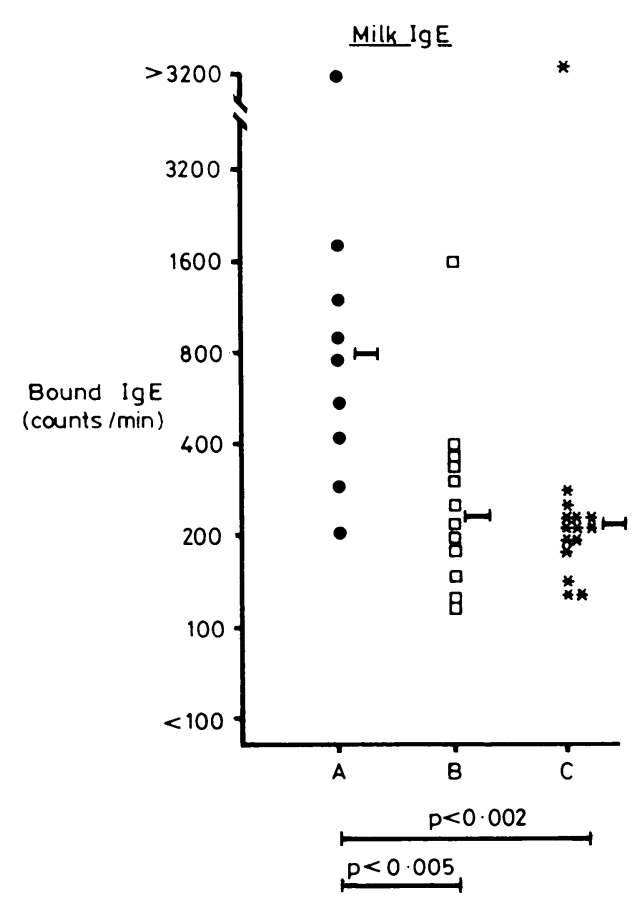

FIG 3-Milk-specific IgE antibodies in the two patient groups and controls measured by radioallergosorbent test.

Our results support Jarrett's hypothesis ${ }^{7}$ and suggest that more than one pathogenic mechanism may operate in allergy to cows' milk.

The patients in group A were almost exclusively breast fed until their introduction to cows' milk and could thus represent a state of low-level allergen exposure. Their initial sensitisation to cows'-milk protein may have occurred in the neonatal nursery or by passage of bovine antigens in their mother's milk. ${ }^{17} 18$ Furthermore, not only have bovine-antigen-containing immune complexes been found to cross the human placenta ${ }^{19}$ but pre- implantation transport of labelled bovine IgG from the mother's stomach to the blastocyst has been traced in pregnant rats. ${ }^{20}$ Thus the assumption that the first experience of dietary antigen is at weaning may be inaccurate.

Four of our children had symptoms consistent with allergy to cows' milk within the first 72 hours of life when they were first given milk in the neonatal nursery. ${ }^{13}$ This suggests that sensitisation had already occurred, and the persistence of this disorder beyond 3 months of age suggests that it was not a passively acquired disease.

Breast feeding is of value in modifying the development of allergic disease in at-risk infants. ${ }^{121}$ Possibly the value of breast feeding would be enhanced by eliminating cows' milk from the diet in pregnancy and while breast feeding. This hypothesis would, however, need to be evaluated in a suitably designed and controlled trial.

Our results, combined with those of studies on the regulation of the $\mathrm{IgE}$ response ${ }^{722}$ and clearance of allergen-containing immune complexes, ${ }^{18}{ }^{23}$ suggest that the aetiology of allergic disease may include several immunological variables. Thus, although transient IgA deficiency may play an important part in the pathogenesis of allergic reactions in some people the question is raised about the validity of this relation as a general hypothesis for the aetiology of allergic disease.

M A Firer is a recipient of a Royal Children's Hospital research award. D J Hill is the recipient of a National Health and Medical Research Council (Aust) applied health science fellowship in allergy. We thank Mrs A Balloch for performing the IgE assays and Miss Georgina Swan and Miss Fay Allinson for typing the manuscript.

\section{References}

${ }^{1}$ Matthew DJ, Taylor B, Norman AP, Turner MW, Soothill JF. Prevention of eczema. Lancet $1977 ; \mathrm{i}: 321-4$.

2 Soothill JF, Stokes CR, Turner MW, Norman AP, Taylor B. Predisposing factors and the development of reaginic allergy in infancy. Clin Allergy $1976 ; 6: 305-19$.

3 Taylor B, Norman AP, Orgel HA, Stokes CR, Turner MW, Soothill JF. Transient IgA deficiency and pathogenesis of infantile atopy. Lancet 1973;ii:111-3.

- Kaufman HS, Hobbs JR. Immunoglobulin deficiencies in an atopic population. Lancet 1970;ii:1061-3. 
5 Stokes CR, Taylor B, Turner MW. Association of house-dust and grasspollen allergies with specific IgA deficiency. Lancet 1974;ii:485-8.

6 Stokes CR, Soothill JF, Turner MW. Immune exclusion is a function of IgA. Nature $1975 ; 255: 745-6$.

${ }^{7}$ Jarrett EEE. Activation of IgE regulatory mechanisms by transmucosal absorption of antigen. Lancet 1977 ;ii:223-5.

${ }^{8}$ Chandra RK. Prospective studies of the effect of feeding on incidence of infection and allergy. Acta Paediatr Scand 1969;68:691-4.

- Swarbrick ET, Stokes CR, Soothill JF. Absorption of antigens after oral immunization and the simultaneous induction of specific tolerance. Gut 1979;20:121-5.

10 Jarrett EEE, Stewart DC. Rat IgE production. I. Effect of dose of antigen on primary and secondary reaginic antibody responses. Immunology $1974 ; 27: 365-81$

11 Jarrett EEE, Haig DM, McDougall W, McNutty E. Rat IgG production. II. Primary and booster reaginic antibody responses following intradermal or oral immunization. Immunology 1976;30:671-7.

12 Walker WA, Isselbacher $\mathrm{KJ}$, Bloch $\mathrm{KJ}$. Intestinal uptake of macromolecules: effect of oral immunization. Science 1972;177:608-10.

13 Hill DJ, Davidson GP, Cameron DJS, Barnes GL. The spectrum of cow's milk allergy in childhood. Acta Paediatr Scand 1979;68:847-52.

14 Shelton MJ, Meek F, Goller I, Hosking CS. Serum immunoglobulin levels in children. Australian fournal of Medical Technology $1974 ; 5: 113-7$.
15 Firer MA, Hosking CS, Hill DJ. Milk specific antibody determination by ELISA : development of an assay. 7 Immunol Methods (in press)

16 Juto P, Bjorksten B. Serum IgE in infants and influence of type of feeding. Clin Allergy 1980;10:593-600.

${ }^{17}$ Hemmings C, Hemmings WA. The transmission of dietary IgG to the $\widehat{\Omega}$ milk and sucklings in rats. IRCS Medical Science 1977;5:247-8.

${ }^{18}$ Jakobsson I, Lindberg T. Cow's milk as a cause of infantile colic in breast-fed infants. Lancet 1978;ii:437-9.

19 Delire M, Cambiaso CL, Masson PL. Circulating immune complexes in infants fed cow's milk. Nature 1978;272:632.

${ }^{20}$ Brambell FWR, Hemmings WA. The passage into the embryonic yolk-sac cavity of maternal plasma proteins in rabbits. $\mathcal{F}$ Physiol $1949 ; 108: 177-85$. $\Rightarrow$

21 Saarinen VM, Kajosaari M, Backman A, Sllmes MA. Prolonged breast- $\mathcal{O}$ feeding as prophylaxis for atopic disease. Lancet 1979;ii:163-6.

${ }^{22}$ Juto $P$, Strannegard $O$. T lymphocytes and blood eosinophils in early $\frac{C}{\sigma}$ infancy in relation to heredity for allergy and type of feeding. $\mathcal{F}$ Allergy $\overline{\bar{S}}$ Clin Immunol 1979;64:38-42.

${ }^{23}$ Paganelli R, Levinsky RJ, Brostoff J, Wraith DG. Immune complexes containing food proteins in normal and atopic subjects after oral challenge and effect of sodium cromoglycate on antigen absorption. Lancet 1979; i:1270-2.

(Accepted 14 April 1981)

\section{Whooping cough in adults}

\author{
B TROLLFORS, E RABO
}

\begin{abstract}
During the 1970s whooping cough returned in Sweden after an absence of more than 10 years and is now seen in all age groups. During a three-year period 174 adults with culture-verified whooping cough were identified in Gothenburg. Most of the patients had typical symptoms with whooping attacks and often vomiting. The disease was long lasting but complications were rare.

Physicians should be aware that whooping cough may occur in adults, since adults may be an important source of infection for infants and erythromycin given in the catarrhal phase may modify the clinical course.
\end{abstract}

\section{Introduction}

A pertussis vaccine giving $90 \%$ immunity was introduced in Sweden during the late 1940 s. $^{1}$ From the early 1960 s about $90 \%$ of all infants were vaccinated and pertussis became rare. In the first years of the 1970s whooping cough returned, and since 1974 the disease has been endemic. The return of the disease seems to have been related to changes in production of the vaccine at the beginning of the decade. ${ }^{2}$

In 1978,5140 bacteriologically verified cases of pertussis were reported to the National Bacteriological Laboratory, Stockholm. Investigation of a subsample showed that out of 620 children aged 1-6 years with the disease, 521 ( $84 \%$ ) had received three injections of pertussis vaccine. Another investigation disclosed that $84 \%$ of 38015 preschool children born during 1974-8 in various regions of Sweden had been given three injections of

Department of Infectious Diseases, University of Göteborg, Ostra Sjukhuset, S-416 85 Göteborg, Sweden

B TROLLFORS, MD, physician

Department of Paediatrics, Västra Frölunda Sjukhus, S-421 44

Västra Frölunda, Sweden

E RABO, MD, physician pertussis vaccine (Epidemiological Department, National Bacteriological Laboratory, Stockholm, unpublished data). Since the Swedish-made pertussis vaccine evidently lacked protective effect, vaccination was stopped in 1979 . When whooping cough returned many adults also contracted the disease.

\section{Patients, methods, and results}

During 1976-8 Bordetella pertussis was isolated from 3488 patients at the Department of Clinical Bacteriology, Gothenburg, which serves a population of just over half a million. This report is based on interviews with all patients aged 20 years and over with cultureverified whooping cough.

Bord pertussis was isolated from 174 adults (51 men, 123 women). Their median age was 35 years, and the range $20-81$. Six patients were over 60 . Twenty-three patients were certain that they had been immunised against whooping cough in childhood during the 1950s. Many patients under 30 had no information about immunisation in childhood but may also have been immunised. Forty-one patients, evenly distributed in the different age groups, claimed with certainty that they had had whooping cough as children.

Ten patients had underlying diseases (five cardiovascular, two rheumatoid arthritis, one diabetes mellitus, one renal insufficiency, one epilepsy). Three women were delivered and one became pregnant $\mathbb{N}$ during active pertussis. Another nine women were pregnant in the second to eighth months.

Most of the patients had had a prolonged illness with whooping attacks and often vomiting (table) but complications were rare. Two

Clinical course of whooping cough in 174 adults (percentages in parentheses)

\begin{tabular}{|c|c|c|}
\hline & $\begin{array}{l}\text { Late or no } \\
\text { erythromycin } \\
\text { treatment } \\
(\mathrm{n}=155)\end{array}$ & $\begin{array}{c}\text { Early erythromycin } \\
\text { treatment (within } \\
\text { four days of onset } \\
\text { of symptoms) } \\
(n=19)\end{array}$ \\
\hline \multicolumn{3}{|l|}{$\begin{array}{l}\text { Severity according to patient's } \\
\text { estimation: }\end{array}$} \\
\hline Mild & $24(15 \cdot 5)$ & $15(78 \cdot 9)$ \\
\hline $\begin{array}{l}\text { Moderate } \\
\text { Severe }\end{array}$ & $57(36 \cdot 8)$ & $2(10 \cdot 5)$ \\
\hline Whooping attacks & $\begin{aligned} 74(47 \cdot 7) \\
127(81.9)\end{aligned}$ & $\begin{array}{l}2(10.5) \\
2(10.5)\end{array}$ \\
\hline Vomiting & $78(50 \cdot 3)$ & $2(10 \cdot 5)$ \\
\hline $\begin{array}{l}\text { Median duration of symptoms in } \\
\text { weeks }\end{array}$ & $8 \cdot 2-26$ & 2. $1-10$ \\
\hline
\end{tabular}

